\title{
Primeros sistemas de reproducción de Arte Rupestre en España
}

\author{
M. ${ }^{a}$ Dolores Moneva Montero ${ }^{1}$
}

Aunque el estudio del Arte Rupestre Prehistórico cuenta con algunos métodos de trabajo tomados de la Ciencia Arqueológica (prospección, excavación), sin embargo exige técnicas propias, encaminadas a conseguir la reproducción, lo más fiel posible, de las manifestaciones gráficas rupestres.

Como parte de un proyecto más ambicioso de reconstrucción de los Inicios Historiográficos del Arte Rupestre en España, estas páginas ofrecen una aproximación a los primeros métodos de trabajo utilizados para la reproducción de estos especiales testimonios del pasado del hombre. Los sistemas considerados son el Croquis, Calco Directo, Fotografía en b/n y color y Molde. El marco temporal elegido abarca desde las más antiguas reproducciones de las que se tienen noticia hasta 1921, año de la Exposición de Arte Prehistórico celebrada en Madrid ${ }^{2}$.

Sin duda, el principal problema al que se enfrenta un trabajo de esta naturaleza es la falta de documentación sobre el tema. Dos son las fuentes de información utilizadas: a) Las propias reproducciones, originales siempre que ello ha sido posible ${ }^{3}, y$ b) Referencias escritas.

\footnotetext{
Becaria F.P.I. Departamento de Prehistoria y Arqueología. Facultad de Filosofía y Letras. Universidad Autónoma. Ciudad Universitaria de Cantoblanco. Telf.: 3974600 - 28049 Madrid.

2 Este estudio forma parte de nuestra Memoria de Licenciatura, presentada en Noviembre de 1992 en el Dpto. de Prehistoria y Arqueología de la U.A.M. bajo la dirección de la Dra. Lucas Pellicer, con el título de Inicios Historiográficos del Arte Rupestre en España. De Altamira a la Exposición de 1921.

${ }^{3}$ En la actualidad llevamos a cabo el estudio de la documentación original sobre Arte Rupestre de la antigua Comisión de Investigaciones Paleontológicas y Prehistóricas (C.I.P.P.) conservada en el Archivo del Museo de Ciencias de Madrid (calcos, fotografías, escritos), con vistas a la realización de nuestra Tesis Doctoral. El trabajo se enmarca en un Proyecto de la D.G.I.C.Y.T. de Recuperación de Fondos Documentales de dicha institución madrileña, bajo la dirección general del Dr. E. Aguirre. El apartado de Prehistoria es coordinado por la Dra. R. Lucas Pellicer.
} 


\section{CROQUIS Y CALCOS ${ }^{4}$}

\section{l.1. Los dibujantes}

Antes de entrar en el análisis detallado de los sistemas de trabajo propiamente dichos conviene dedicar algunos párrafos a todos aquellos nombres que, con grandes dosis de esfuerzo y dedicación, hicieron posible la realización de estas obras.

Se impone una distinción previa entre aquellos que trabajan de forma más o menos ocasional (descubridores, prospectores, ciertos Prehistoriadores) y quienes se dedican a esta labor de forma continuada, pudiéramos decir "profesional». Es en estos últimos en quienes se centra nuestra atención.

No deja de sorprender el hecho de que sea precisamente en los primeros momentos de desarrollo de este nuevo campo de la Prehistoria que es el estudio del Arte Rupestre cuando surgen algunas de sus más destacadas figuras. Se trata de nombres tan conspicuos como los de $\mathrm{H}$. Breuil (1877-1961), J. Cabré Aguiló (1882-1947), H. Alcalde del Río (18661947), Fco. Benítez Mellado (1883) ${ }^{5}$ y E. Campo Sobrino (1890-1910) ${ }^{6}$, auténticos pioneros cuya actividad se prolonga a lo largo del tiempo, marcando el camino que, con los lógicos adelantos técnicos, se ha mantenido en gran medida hasta nuestro días ?

Varios son los aspectos que caracterizan a esta primera generación de dibujantes de Arte Rupestre.

1) Muchos de ellos cuentan con una inicial formación artística ${ }^{B}$.

Lamentablemente, no se cuenta con reproducciones de esta valiosa documentación que esperamos poder ofrecer próximamente.

4 El análisis conjunto de ambos métodos de trabajo se justifica por la frecuente dificultad para determinar si el origen primero de ciertos dibujos está en el calco o el simple croquis.

5 Benitez Mellado, Ayudante Artístico de la C.I.P.P. desde 1915, cargo al que accede por Oposición. La documentación original de este dibujante se conserva en el Museo de Ciencias de Madrid. Sobre su figura, consúltese: Benítez Mel!ado, 1959.

- Campo Sobrino, gran dibujante pontevedrés que trabaja para la Sociedad Arqueológica Provincial. Sus obras se conservan en el Museo Arqueológico de la ciudad. Vide: Cataloguillos de Exposiciones, 1940. Algunas obras de Campo Sobrino son reproducidas por Sobrino Buhigas en el famoso Corpus de 1935 y, posteriormente en FILGUEIRA, J.; GaACiA ALEN, A. 1956 Carta Arqueológica de la Provincia de Pontevedra y García Alen, A.; Peñ Santos, A., 1980.

Aunque $E$. Hernández-Pacheco no fue negado para este tipo de trabajos, prefirió dejarlo en manos de colaboradores: su hijo Francisco (fotografias) y Benitez Mellado (dibujos).

8 Alcalde del Río estudió con el paisajista Carlos Haess, fundando posteriormente la Escuela de Artes y Oficios de Torrelavega; Juan Cabré pasó por la Escuela de San Fernando y entre los maestros de dibujo de Benítez Mellado, se cuenta el propio J. Sorolla. 
2) Algunos llegarán a ser grandes Prehistoriadores (Cabré, Alcalde y especialmente BreUIL); otros tan sólo dibujantes (Benítez y Campo). Pero estos últimos contarán siempre con la supervisión de especialistas en la materia, papel desempeñado por E. Hernández-Pacheco en el caso de Benítez y por el arqueólogo pontevedrés Casto Sampedro, en el de E. Campo.

3) Autodidactas en el campo que nos ocupa, en todos ellos se conjuga un talento natural para el dibujo con grandes dosis de decisión y valentía a la hora de emprender este novedoso trabajo de reproducción de las manifestaciones prehistóricas rupestres. Tan sólo en $\mathrm{H}$. Breuil se puede reconocer un cierto papel docente, pues, tanto Alcalde del Río como J. Cabré se inician en estas labores bajo el consejo del prehistoriador francés, como reconoce el propio Alcalde en el artículo de Portugalia de $1906^{9}$. De cualquier manera, de ese gran talento para el dibujo han quedado testimonios en otros campos de la Prehistoria.

4) Ingente labor acometida, que, en algunos casos, supera los límites de nuestro país. La escasa producción de Alcalde del Río se compensa por la alta calidad metodológica alcanzada. En general, todos estos dibujantes están abiertos a los diversos ciclos y áreas peninsulares, con las excepciones de $\mathrm{H}$. Alcalde y $\mathrm{E}$. Campo, centrados en la zona cantábrica y en Pontevedra, respectivamente.

5) Obra muy desigualmente valorada. Valga como ejemplo la escasa preocupación de que han sido objeto Benitez Mellado y Campo Sobarino, frente al unánime reconocimiento de la figura del abate Breuil como dibujante.

\subsection{El croquis o dibujo a mano alzada}

Sin duda es el primer sistema empleado para la reproducción de manifestaciones rupestres prehistóricas, aunque algunos investigadores pongan en duda el valor científico del croquis por el amplio margen de subjetividad que permite al dibujante (CHABREDIER 1966; LEROI GOURHAM 1965).

Se trata del método elegido en los trabajos más antiguos (fig. 1), cuyo uso se va generalizando especialmente entre aquellos no expertos en el

9 Por su parte, los comienzos de H. Breuil como dibujante de Arte Rupestre, no muestran la presencia de maestros que le inicien en la tarea. La formación y primeros ensayos del Abate tienen lugar en una serie de cuevas paleolíticas francesas: La Mouthe, Combarelles, Font-deGaume y Marsuolas, entre 1900-1902, año en que viene a Altamira, donde realiza el que, sin duda, será uno de sus más famosos trabajos. 

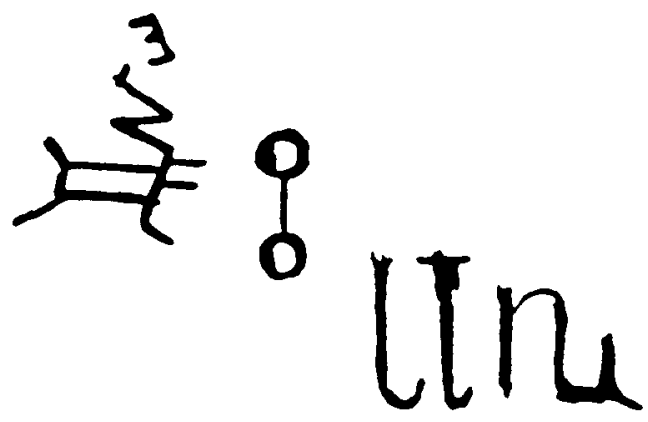

00

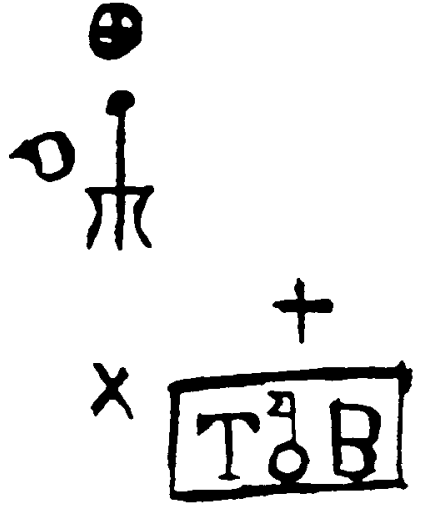

Fig. 1. Laxe das Chaves de San Pedro según el P. Sarmiento (Garcia Alen y Peña Santos, 1981, fig. 63).

tema (prospectores, descubridores e informadores de todo tipo), que tienen que hacer una reproducción más o menos válida de las manifestaciones rupestres, como prueba de la veracidad del hallazgo ${ }^{10}$.

Esto no quiere decir que los especialistas no recurran también a este método de trabajo justificando la elección con los más variados razonamientos, desde la gran complejidad de los frisos, que lleva a Breuil a

10 La más antigua copia de Arte Rupestre conservada parece ser la del petroglito de Laxe das Chaves de San Pedro, que incluye el erudito P. Sarmiento en su obra Viaje a Galicia 1745. 1754. Más conocidos son los dibujos de las pinturas de Fuencaliente de $F$. López de Cárdenas, el Cura de Montoro, fechados en 1783. También de estos momentos, y quizá algo anteriores, son algunas reproducciones de diferentes enclaves canarios, como la cueva de Belmaco, que publica D. Mariano Nogués y Scallas en 1879. 
elegirlo en San García (Burgos) en junio de 1912, a la inaccesibilidad de los motivos, causa de que repita el método poco tiempo después en la cueva de Bolao (Asturias). También se tendrá en cuenta el posible peligro de destrucción de los motivos a la hora de decidirse por este sistema. Es claro que la "Copia a Mano Alzada" se reserva mayoritariamente para los soportes más frágiles, optándose por el Calco Directo cuando la resistencia de la roca así lo permite.

Sin duda uno de los más famosos conjuntos de reproducciones a mano alzada que ha quedado de estos primeros momentos es el de los Polícromos de Altamira. Efectivamente, fueron muchos los especialistas y aficionados atraídos por la perfección de estas figuras que quisieron reproducirlas recurriendo a este procedimiento. Así: Ratier, $1879^{11}$; Sanz de Sautuola, ant. $1887^{12}$; Argumosa, septiembre $1880^{13}$; el hijo del Conde de Moriana, octubre $1880^{14}$; E. Harlé, marzo-abril $1881^{15}$; Reyes y Prósper, $1890^{16}$; Breuil y Cartailhac, octubre $1902^{17}$ y Alcalde del Río, novdic. $1902^{18}$ (fig. 2). Cuando en 1923 la Comisión de Investigaciones Paleontológicas y Prehistóricas (C.I.P.P.) se decida de nuevo a trabajar en la caverna, recurrirá al mismo método de trabajo con el auxilio de numerosas medidas.

\subsection{El calco directo o por contacto}

Como señala Aujoulat, el frecuente recurso al calco directo para la reproducción de los motivos parietales se explica por las grandes ventajas

A partir de los dibujos de Ratier se hacen las planchas $3 .^{a}$ y $4 .^{a}$ del folleto de Sautuola. En la entrada del Museo Arqueológico de Santander se expone un óleo del techo de los polícromos, obra de Ratier a juzgar por las referencias de Carballo (1950), si bien el cartel de Museo atribuye la obra al erudito y bibliófilo montañés, E. de la Pedraja.

12 No parece improbable que el propio Sanz de Sautuola hubiese tomado algunas notas de las figuras y, así se le atribuye un bisonte enviado a Piette en 1887 , si bien es cierto que, desde los primeros momentos, Sautuola buscó a alguien que pudiera hacer una reproducción exacta de los motivos rupestres.

3 Rodriguez Ferrer, M., La Ilustración Española y Americana, 8-X-1880; fig.2, Anónimo, Alrededor del Mundo, 21-XI-1902, fig. 2.

4 Rios y Rics, A., El Eco de la Montaña, 14-X1-1880

15 HARLE, Materiaux pour l'Histoire Primitive del Homme, XII, 1881.

16 Dibujante del Museo de Ciencias de Madrid, cuya obra quedó en manos del naturalista L. Hoyos Sainz.

7 Cartailmac, E. et. Breull, H. 1906: La caverne d'Altamira à Santillana. En la actualidad, estos pasteles se encuentran en los archivos del Museum d'Histoire Naturelle de París, sin catalogar y en mal estado de consevarción, por lo que no se permite la consulta de los mismos.

Conjunto de 24 planchas a color de cada una de las figuras aisladas y una de todo el conjunto que se conservan, en excelente estado, en el Museo de Altamira. Seis de los pasteles fueron publicados por B. Madariaga en 1972 (vide pág. 33 de dicha obra), pero en unas condiciones que difícilmente permiten apreciar la gran calidad de la obra de Alcalde 

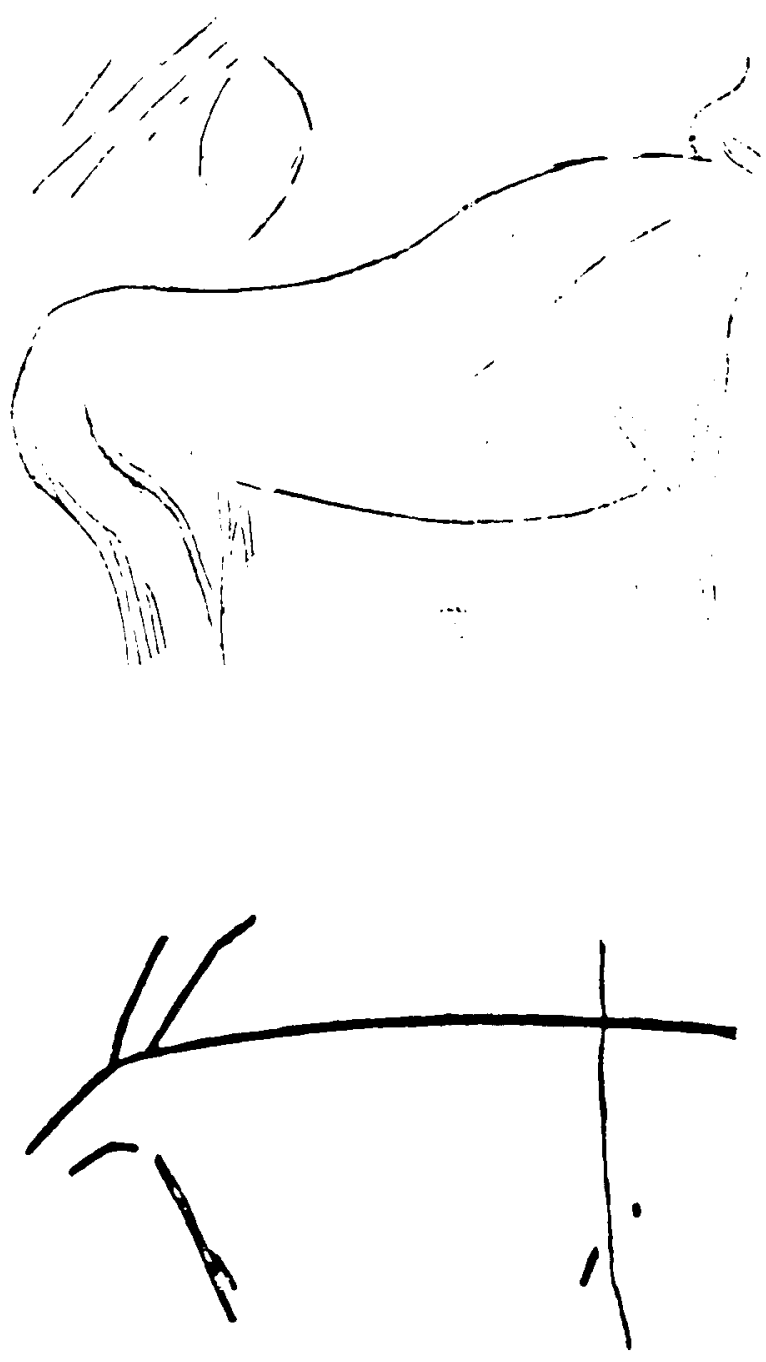

Fig. 2. Altamira: bisonte y cáprido según Sanz de Sautuola y Harlé (Madariaga y Sanemeterio, 1976, pág. 41; Harlé, 1881; p/ VIII).

de un método de trabajo «fácil de hacer, en un tiempo corto, con resultados inmediatamente explotables, fácil de analizar y de publicar" (1987, 17).

Sistema utilizado indistintamente para la reproducción de grabados y pinturas, salvo en algunos casos muy concretos en que la fragilidad de 
las manifestaciones artísticas o del propio soporte hacía temer por la integridad del conjunto.

Ya se ha visto cómo en Altamira se opta mayoritariamente por el croquis para la reproducción de los Polícromos, pero, sin embargo, queda constancia escrita del uso del calco directo para algunos motivos pintados. Breuil y Cartailhac calcaron varios zoomorfos y signos pintados de la caverna en octubre de 1902. Se trata, además, de una de las primeras veces en que, con seguridad, se constata la utilización de dicho sistema de trabajo, ampliamente utilizado con posterioridad.

Todas las reproducciones ejecutadas hasta 1921 en Cogul (Lérida) son fruto de este sistema de trabajo: Rocafort y Soler 1907, a partir del cual L. Izquierdo hace un dibujo en 1908, y J. Cabré en 1912 para el Institut de Paléontologie Humaine de París. A ellos se suman otros muchos ejemplos, como los calcos de varios canchales salmantinos (Cabras Pintadas, El Cristo y el Zarzalón), realizadas por Breuil y Cabré.

El calco va a ser el método de trabajo preferido por la Comisión de Invesatigaciones Paleontológicas y Prehistóricas, aunque con ciertas variaciones impuestas por las propias circunstancias de cada ciclo artístico. Como explica E. Hernández-Pacheco en 1959, las manifestaciones Paleolíticas y Esquemáticas no presentan problemas debido al buen estado de conservación, con lo que, salvo excepciones, basta con el simple calco directo. La mayor dificultad se presenta en el caso de las pinturas Naturalistas (Levantinas), de ahí que se perfeccione el sistema, complementándose con el dibujo previo a la vista del original, siendo necesario, de nuevo según palabras de $\mathrm{E}$. Hernańdez-Pacheco, humedecer e incluso empapar bien la roca (el subrayado es nuestro). El Museo de Ciencias de Madrid conserva un lote de fotografías de Fco. Hernández-Pacheco que ilustran este proceso y que fueron obtenidas durante la campaña de trabajo en las Cuevas de la Araña en el verano de 1920, buena parte de las cuales publica Hernández-Pacheco en la monografía aparecida cuatro años después (fig. 3).

\subsection{Valoración crítica de dibujos y calcos}

\section{a) Medios (Soportes y Útiles/Técnicas)}

Gran diversidad de soportes: papel de calco, de dibujo, cartulinas, simples hojas de apuntes e incluso de libros. Los originales del Museo de Ciencias de Madrid prueban una clara política de reutilización que lleva en ocasiones a hacer uso de ambos lados del papel o a recortar las hojas 

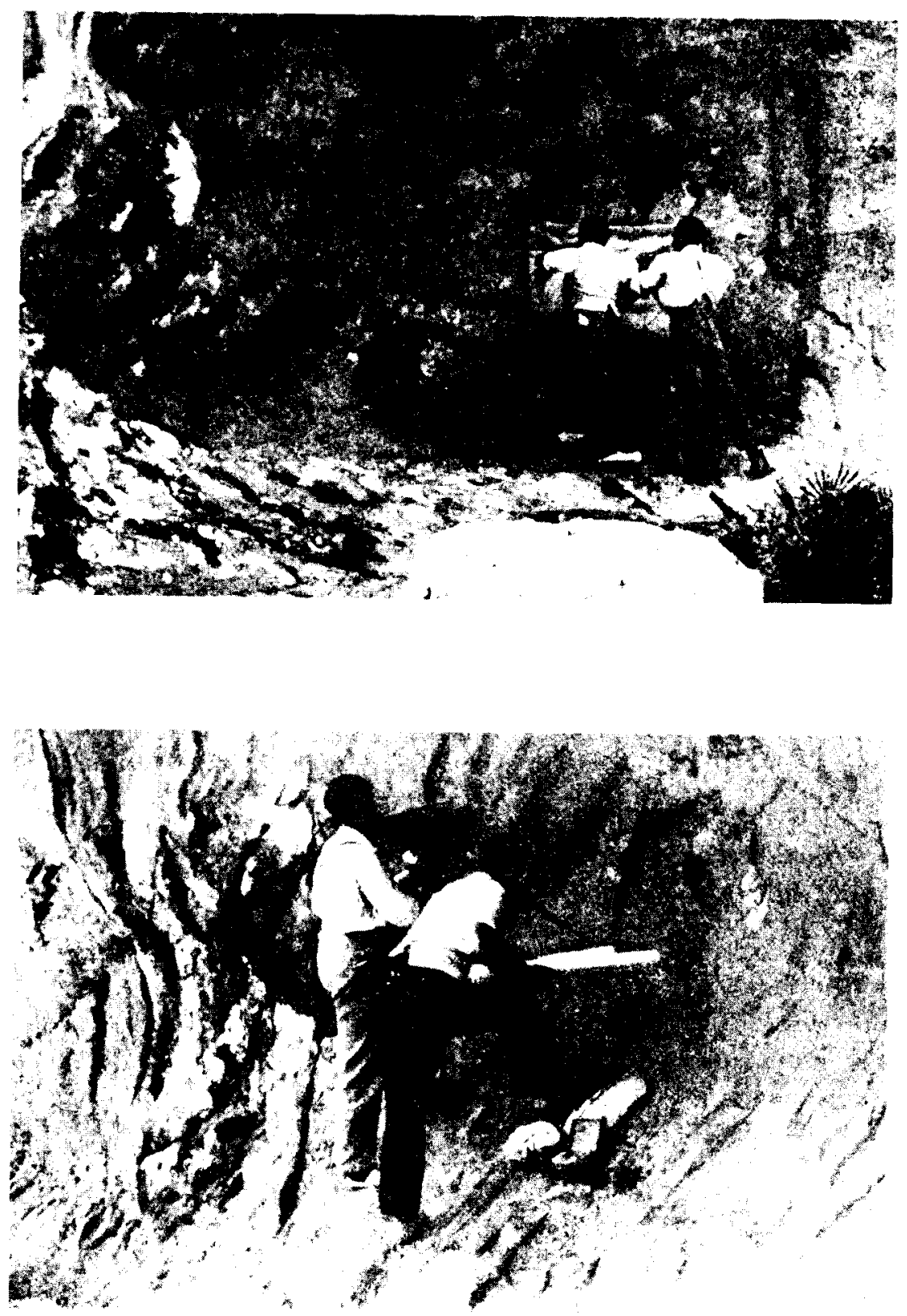

Fig. 3. Benítez Mellado durante el proceso de calco de las pinturas de las Cuevas de la Araña (Hernández-Pacheco, 1924; figs. 5 y 8). 
siguiendo el perfil de los motivos. Valga como ejemplo una lámina de la Garganta de la Hoz (Aldeaquemada, Jaén), obra de J. Cabré, con motivos por ambos lados, aunque sólo uno de ellos fue finalmente publicado.

Respecto a los medios escriptóreos o elementos de dibujo se constata el uso de lápices y tintas de diferentes colores, con un claro predominio del negro, carboncillos, ceras, acuarelas o pasteles, cuya elección venía impuesta en gran medida por las condiciones particulares de cada estación artística. En Altamira, según relato del propio Abate Breuil, la excesiva humedad obliga a sustituir las acuarelas por pasteles, obteniéndose el negro a partir de carbón de madera o corcho quemado.

Probablemente sean éstas las más famosas reproducciones en color, pero no las únicas, si bien lo cierto es que la inmensa mayoría de lo publicado aparece en blanco y negro, sin duda debido a cuestiones económicas. De hecho, revisando los fondos del Museo de Ciencias se encuentran los originales en color de muchas de las láminas posteriormente publicadas en blanco y negro.

Uno de los más aficionados a la policromía de Fco. Benítez Mellado, quien, en el caso de las pinturas naturalistas, trataba de hacerlas tal y como se veían cuando están humedecidas, para que resultaran copias fieles y exactas del original (HERNÁNDEZ-PACHECO 1959).

\section{b) Contenido}

La atención se centra fundamentalmente en los motivos antrópicos y en menor medida en el soporte rocoso.

Son escasas las reproducciones de grandes conjuntos o paneles completos y se tiende a la selección de motivos aislados o bien de pequeños grupos, lo que dificulta enormemente la visión de conjunto (fig. 4).

A ello se suman frecuentes reconstrucciones, en ciertos casos abusivas. La C.I.P.P. no era demasiado partidaria de las reconstrucciones, al menos cuando éstas se realizaban en exceso, como explica HernándezPacheco con motivo de las copias que Benitez hace en Tivissa (Tarragona) en octubre de 1921: "Hemos preferido copiar lo existente a caer en una interpretación que, con la mayor buena fe, pudiera ser errónea. Creemos que en la copia de las pinturas rupestres debe procederse con la mayor circunspección y que vale más dejar sin interpretar lo borroso y confuso, copiando sinceramente lo que se ve, que esforzarse en seguir las porciones en extremo perdidas y difuminadas, para completar, lo que, obsesionándose por el aspecto de la mancha borrosa, se cree ver (HERNÁNDEZ-PACHECO 1924, 345). 


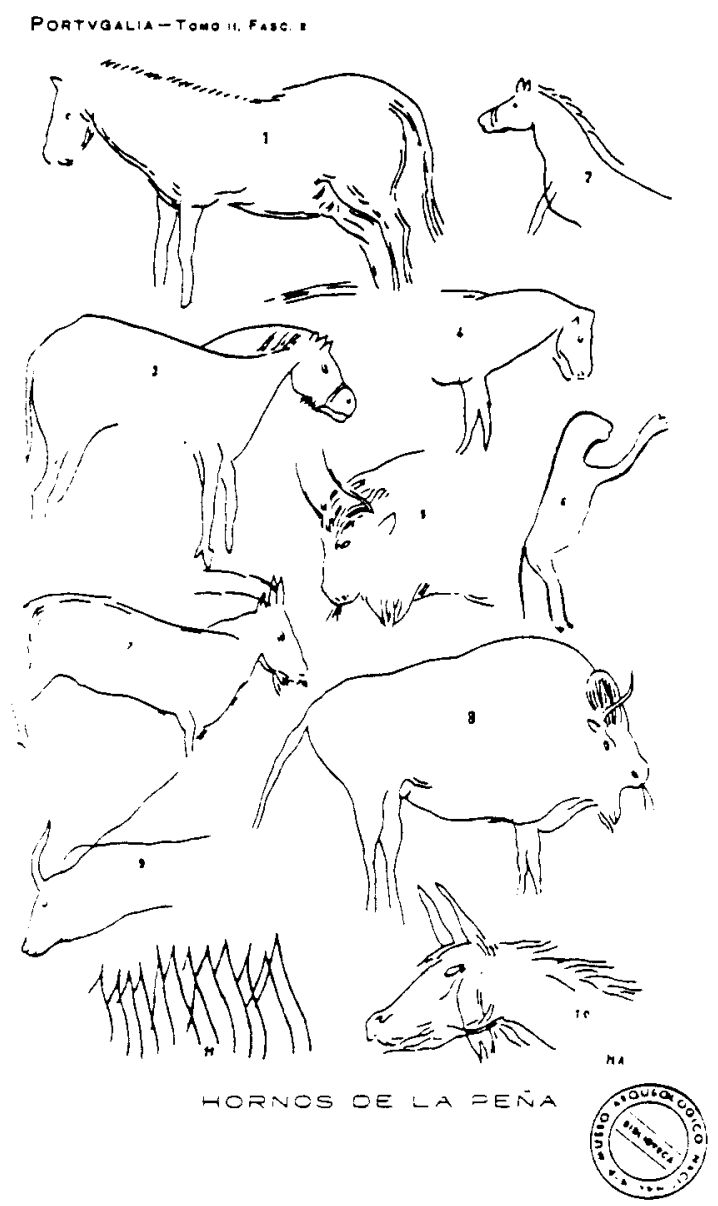

Fig. 4. Hornos de la Peña: selección de motivos según Alcalde del Rio (1906, est. $X I)$.

En varias ocasiones Benítez Mellado, a las órdenes de E. HernándezPacheco, volverá a copiar ciertos conjuntos que habian sido objeto de reconstrucciones sucesivas, fallo del que frecuentemente se acusa a $\mathrm{Ca}$ bré.

Efectivamente, J. Cabré es el más dado a la reconstrucción, sin previa advertencia en muchos casos, como se observa en las sucesivas copias de La Roca dels Moros de Calapatá (Teruel), publicadas en los años 1907, 


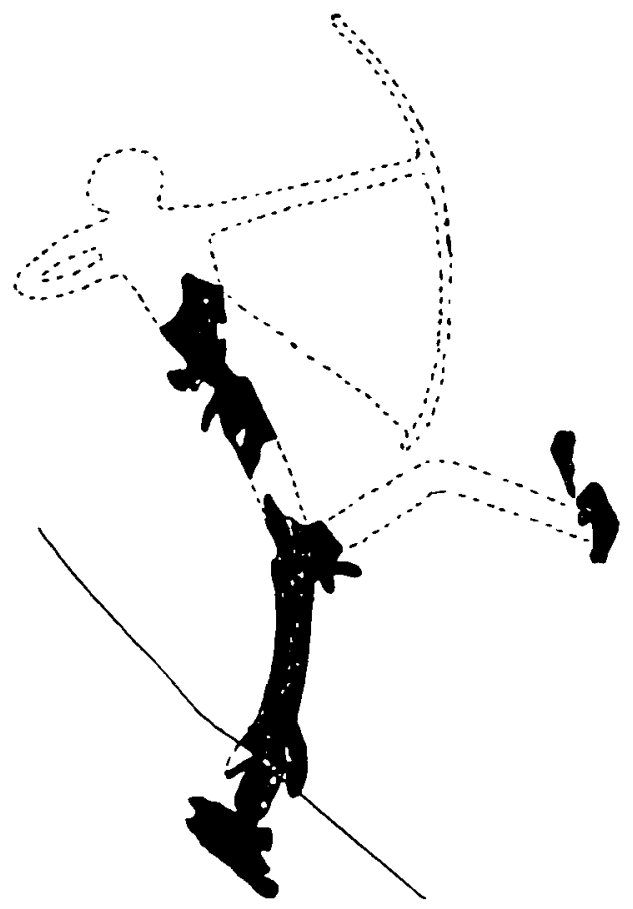

Fig. 5. La Araña: reconstrucción de un "arquero» según Benitez Mellado (Hernández-Pacheco, 1924; fig. 51).

1909 y $1915^{19}$ : en la primera se sirve de una tenue línea de perfil que deja las partes perdidas sin hacer; en la segunda los ciervos están más perfilados y rellenos de color, aunque se marca con línea de puntos lo reconstruido mientras que la última ofrece unas figuras perfectamente acabadas.

Sin embargo, también en algunas ocasiones Benítez Mellado cae en una excesiva reconstrucción, siendo uno de los casos más llamativos el de unos leves restos humanos de una de las cuevas de La Araña (Valencia) que le "permiten" dibujar un arquero idisparando! (fig. 5).

Dejando al margen el posible intento de plasmar el fondo rocoso en la cueva almeriense de los Letreros por parte de Góngora y Martínez

19 Vide: Bol. H. ${ }^{a}$ y G. del Bajo Aragón, L'Anthropologie y El Arte Rupestre en España, respectivamente. 


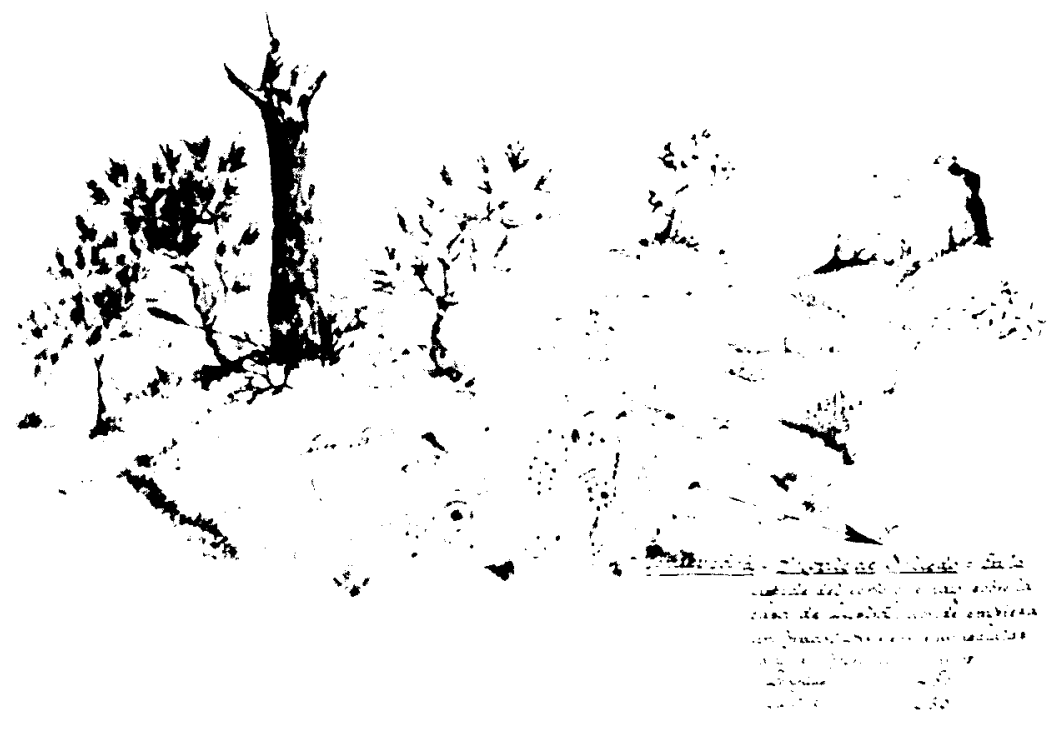

Fig. 6. Petroglifo de Salcedo según E. Campo (Garcia Alen y Peña Santos, 1981, fig. 114).

(1868, figs. 81 y ss.), es sin duda al pintor Ratier a quien corresponde el mérito de haber sido el primero en prestar atención al soporte rocoso en las reproducciones de Arte Prehistórico, aspecto que tampoco olvida Enrique Campo, quien llegará a realizar auténticas "fotografías" con los petroglifos, los árboles y el cielo (fig. 6), procedimiento que, de alguna manera, pone el acento en el soporte y entorno de las manifestaciones gráficas prehistóricas, tal y como se tiende a hacer en la actualidad, si bien en la mayoría de los casos el fondo sigue siendo el de la superficie lisa del papel.

Pero junto a los motivos artísticos propiamente dichos aparecen también otros elementos de gran interés por la información que de ellos se puede extraer, como es el caso de escalas, medidas, orientación, etc.

Muchísimos dibujos carecen de escala y otros se reproducen a tamaños muy diversos, con lo cual resulta difícil establecer comparaciones, incluso entre motivos de una misma estación artística. En San Román de Candamo las reducciones oscilan entre 1:2 y 1:18 del tamaño natural y ni siquiera en todos los casos se mencionan las proporciones. De cualquier manera, siempre que aparece la escala es numérica, jamás gráfica. 


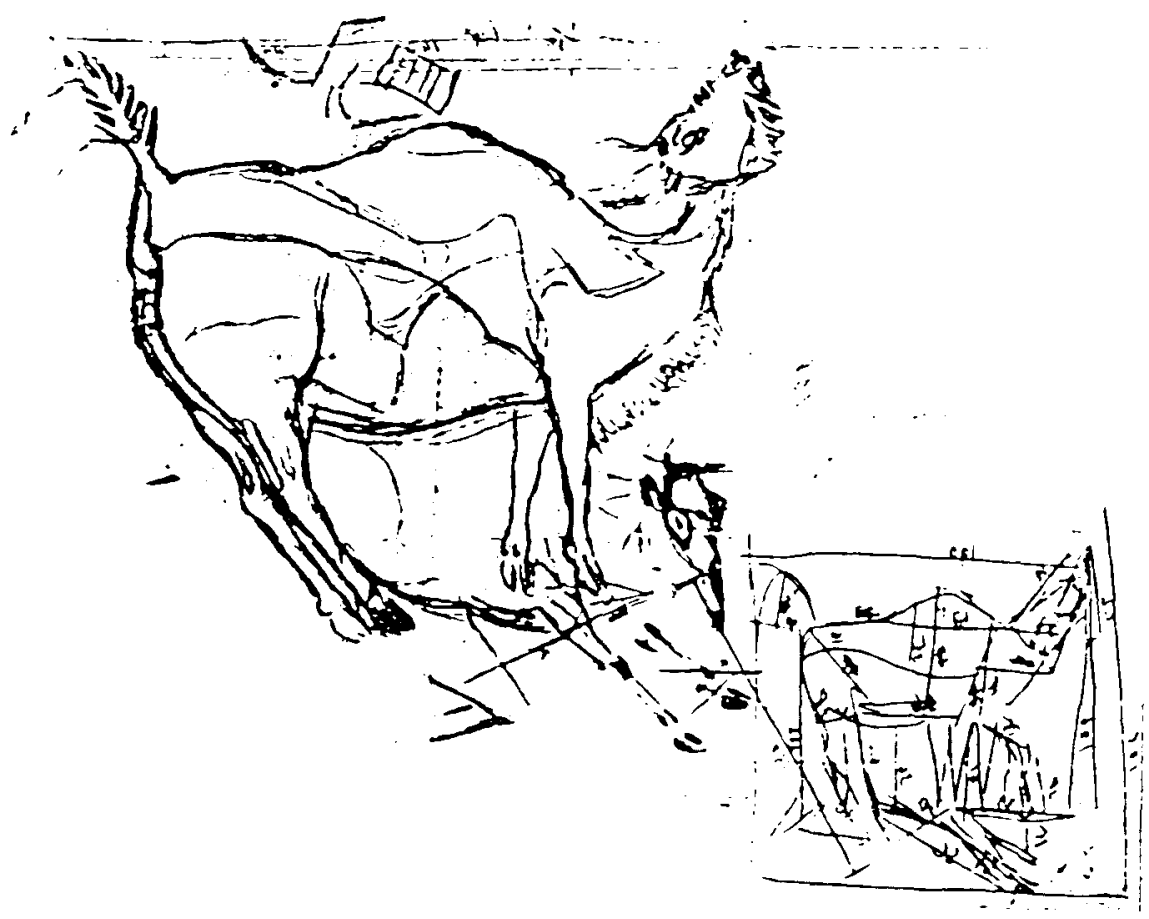

Fig. 7. Altamira: croquis de un bisonte según Breuil (Cartailhac y Breuil, 1906, fig. 62).

Tampoco es corriente que se recojan toda una serie de medidas como longitud, altura o distancia entre motivos. Se sabe que $\mathrm{H}$. Breuil apuntaba todos estos datos en sus croquis, eliminándolos en el momento de la publicación (fig. 7).

Más infrecuente es la orientación de las láminas. La más antigua referencia al respecto se encuentra en los pasteles de altamira de Alcalde del Río, pues en ocho de los veinticinco que forman el conjunto se han marcado los puntos cardinales en los extremos de las hojas. Otros ejemplos posteriores son los de Jesús Carballo en sus reproducciones de Atapuerca (1910, fig. 6), L. M. Vidal en la roca de Capmany (1914, fig. 2) y especialmente Enrique Campo en varios petroglifos, como el de la Pedra dos Mouros (Paredes) y la Laxe do Outeiro do Mato das Cruces (Salcedo) (García Alen y Peña Santos 1981 , figs. 113 y 128).

c) Símbolos de Representación Gráfica 
Si bien se puede aceptar la existencia de unas primeras claves o símbolos destinados a facilitar la lectura de las reproducciones, no se puede hablar de una normativa fija a la que se ajusten los trabajos, ni a nivel general ni casi a nivel de cada autor, libertad metodológica a la que no es ajena la investigación actual ${ }^{20}$. Así, cada investigador trata de adaptar individualmente su obra al original rupestre, recurriendo a toda una serie de recursos, como línea de puntos, trazo continuo, color plano o graduado, incluso auténtico modelo, si así lo hicieron los artistas prehistóricos.

Generalizando, se pueden resumir las siguientes claves:

- Para la reproducción de los motivos pintados se opta mayoritariamente por el uso del color: plano (Cabré o Breuil) o marcando los saltados de la roca (Benítez Mellado). En ocasiones se traza sólo el perfil de la figura, recurriendo a un haz de líneas o a una sola línea y muy esporádicamente se diferencia el ancho de los trazos pintados (fig. 8).

- En el grabado, lo más corriente es recurrir a la técnica del doble trazado de grosor desigual, aunque no faltan ejemplos de doble línea de igual espesor o de múltiples líneas, en este último caso con una de mayor tamaño para diferenciar grabado de pintura, sin que jamás se incluya la sección del grabado.

En ocasiones la clave para expresar la diferenciación técnica debe buscarse en el diferente material de dibujo seleccionado: lápiz para la pintura y. tinta para el grabado, o bien lápices de diferente grosor para cada una de las técnicas. De la primera solución queda buen ejemplo en las copias de la caverna de Santimamiñe, obra de Aranzadi, Barandiarán y Euguren, mientras que el segundo recurso es utilizado por Cabré y Benítez en San Román de Candamo.

El trabajo de Ratier en Altamira en 1789 se puede considerar como el primer intento de plasmar la diversidad técnica utilizada por el hombre prehistórico. Las figuras pintadas se rehacen a base de línea de perfil en lápiz negro, mientras que el grabado se individualiza por la utilización de una línea de perfil blanca (fig. 9).

- Fondo del soporte: el recurso más frecuente consiste en aplicar al papel una tonalidad base, simulando la de la roca original, con el fin de

20 Tanto C. Servelle (1990) como G. y B. Delluc (1984) hablan de la existencia de una auténtica "cartografía", esto es, de todo un conjunto de signos o símbolos convencionales que permiten la traducción gráfica de las observaciones del investigador ante el examen del original rupestre. 

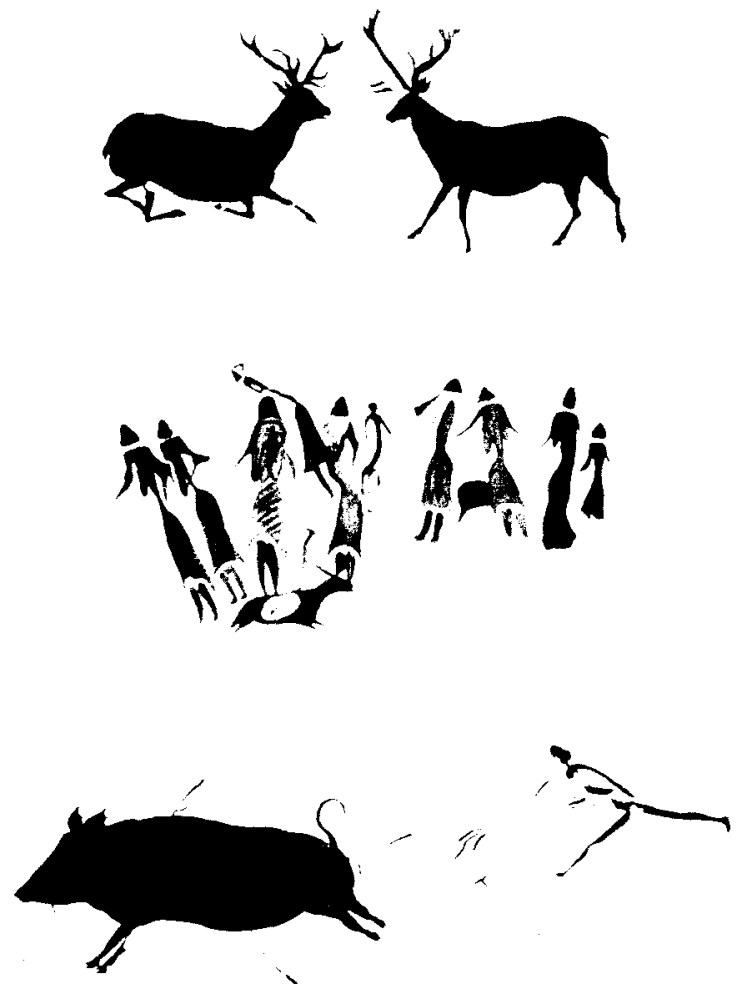

Fig. 8. Cretas, Cogul y Val del Charco según J. Cabré (Catálogo Exposición Arte Prehistórico, 1921, lam. XVI).

evitar que las figuras destaquen en exceso, tal y como se puede observar en los pasteles de Altamira de Alcalde del Río. Quizá J. Cabré pretende lo mismo mediante el uso de lápices amarillos, anaranjados e incluso imorados! en tres cartones de San Román de Candamo, conservados en el Museo de Ciencias. El recurso al color de fondo fue casi norma de la C.I.P.P. en la abundante producción de Arte Levantino.

- Las lagunas o pérdidas son objeto de varias soluciones: elección de un tono más claro, rayado o reconstrucción a base de línea de puntos.

- No es infrecuente que se preste atención al estado de conservación de los conjuntos gráficos mediante la gradación de intensidad del colorido aplicado.

Uno de los trabajos de los que más información se dispone al respecto es del de Benítez Mellado en La Valltorta (Castellón), cuyas claves se 
OBJETOS PREMISTÓRICOS EN LA PRUVIKCIA DE SANTANDER 1 , aIIIII. I:"

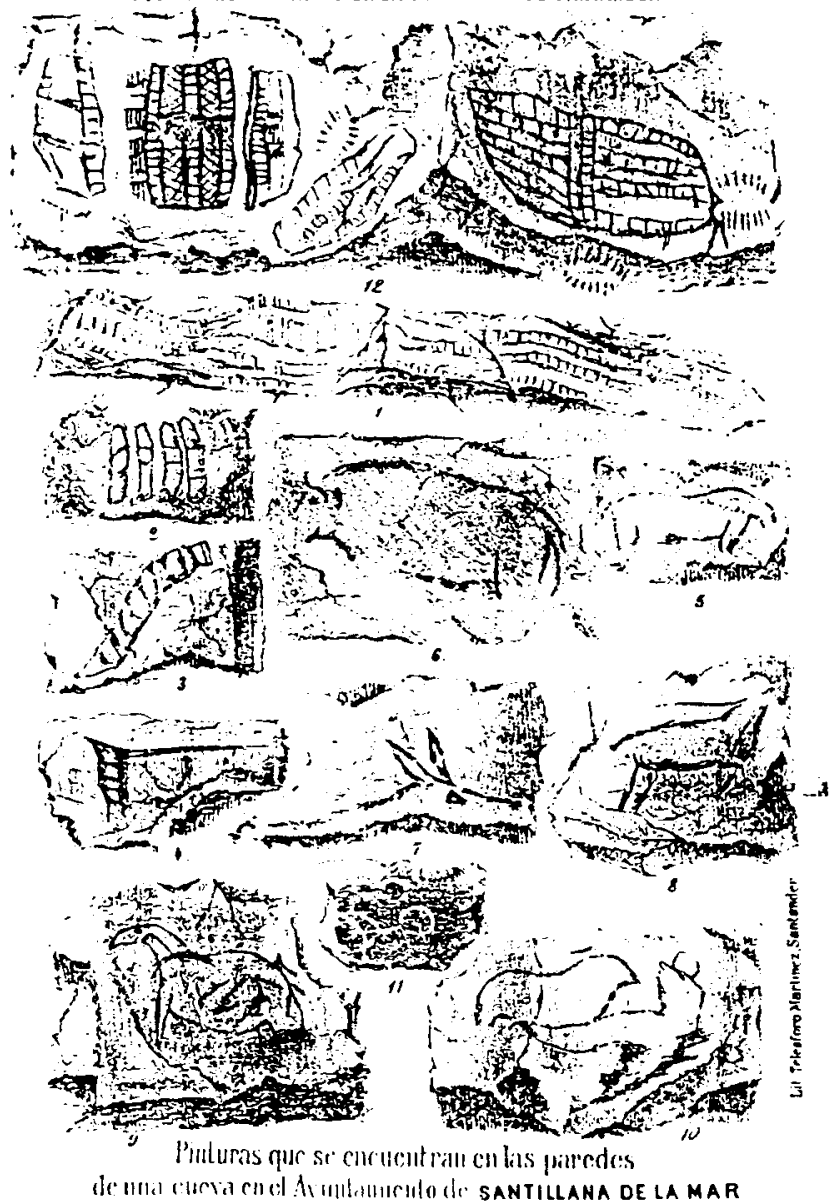

Fig. 9. Altamira: pinturas y grabados según Ratier (Sanz de Sautuola, 1880, lám. 3. $\left.{ }^{\mathrm{a}}\right)$.

recogen en la monografía aparecida en el año 1919: color negro para las pinturas bien visibles, que se va aclarando conforme la conservación de éstas empeora; si los contornos de las figuras son inseguros, no se limitan las líneas; las porciones saltadas se marcan con líneas paralelas y, donde no hay más remedio que reconstruir, se utilizan las líneas de puntos. También es frecuente que se preste atención al soporte rocoso. Además, cada lámina está numerada, indicándose su posición respecto a las demás para reconstruir el conjunto; se numera cada figura y se señalan distancias 
entre ellas y con respecto a determinados puntos del soporte rocoso. Se hace referencia a los saltados, a la posible modernidad de ciertos motivos, a la intensidad del colorido, etc.

Pero los dibujantes no siempre se atienen a una misma normativa, y así, en 1918, en Doña Trinidad (Málaga), H. Breuil rompe con lo que había sido hasta la fecha su forma habitual de hacer, adoptando unos criterios muy arbitrarios: trazo vertical para el color amarillo y horizontal para el rojo, con una densidad variable según el estado de conservación, simbología que no volverá a aplicar posteriormente el prehistoriador francés.

Lamentablemente muchos de estos detalles se pierden en el momento de la publicación, de ahí el interés del estudio de los originales para sacar a la luz muchos datos sobre la metodología seguida. Asi es corriente que perfilen previamente los motivos en lápiz negro o rojo para detallarlos posteriormente. En algunas ocasiones cometen errores que se rectifican, bien sobre el mismo dibujo, borrando y rehaciendo de nuevo, o bien en otra lámina. En Bicorp (Valencia), Benítez Mellado llegó a reproducir tres veces el mismo corzo de la primera covacha, "aclarando" progresivamente los saltados y grietas de la roca hasta lograr la claridad deseada (HERNÁNDEZ-PACHECO, E. 1924, lám. XIII).

\section{d) Autoría}

No es corriente que los trabajos vayan firmados, siendo Bemítez Mellado y Campo Sobrino los que más veces consignan el nombre y, más ocasionalmente, Breuil, Cabré y Alcalde del Río. No parece casual que sean precisamente los que se dedican en exclusiva a las tareas de reproducción los que estampen sistemáticamente la firma en un claro deseo de obtener el reconocimiento por su "buen hacer artístico".

Si bien nadie niega al autor de una fotografía el derecho a poner su nombre en la misma, la cuestión no parece tan clara por lo que se refiere a los dibujos y calcos, al menos en estos primeros momentos. La única opinión al respecto se debe a Aranzadi, Barandiarán y Euguren (1925) y es contraria a la firma del copista moderno, como modo de respeto al anónimo artista prehistórico.

Al margen de esta discusión, es un hecho evidente que la ausencia de firma u otro elemento identificativo dificulta la correcta atribución de ciertos lotes de dibujos, problema que afecta especialmente a Breuil y Cabré, pues ambos realizan numerosas campañas juntos y además comparten una simbología muy semejante. 
e) Fidelidad

Aunque en términos generales, la valoración de todo este material resulta claramente positiva, no se puede dejar de mencionar algunos aspectos que limitan la objetividad y, por tanto, el valor científico del mismo.

Es frecuente que se eliminen figuras, bien por la dificultad que imponen las superposiciones, bien por un menor interés e incluso desprecio por determinados motivos, precisamente los más esquemáticos. De hecho, ninguna de las copias realizadas en Cogul por estas fechas presta atención a los numerosos letreros que aparecen en los paneles y que no serán reproducidos hasta algún tiempo después. En otros casos, conjuntos muy parecidos aparecen perfectamente claros en las láminas. Pero entonces se echa de menos la referencia a la reconstrucción que, en algunos casos, por excesiva, resulta inadmisible. Sin olvidar que no siempre respetan distancias, tamaños o disposición de motivos. Ejemplos de diferentes lecturas, como la de los supuestos animales cuaternarios de Cogul y Alpera defendida por $\mathrm{H}$. Breuil, ponen de relieve la sugestión que a veces les imponían sus propias teorías en la lectura de estas manifestaciones gráficas.

A pesar de todo, no se observan grandes diferencias en los resultados, a no ser las lógicas de toda tarea realizada por distintas personas. Un rápido cotejo de los pasteles de Altamira de $\mathrm{H}$. Breuil y Alcalde del Río pone de manifiesto el mayor detallismo del primero, mucho más exhaustivo, atendiendo a las superposiciones por pequeñas que éstas sean, pero sin que quede la menor duda de que lo que se ve en ambos casos son los mismos motivos.

De cualquier manera, los propios dibujantes no dudan en reconocer la existencia de toda una serie de problemas en la aplicación de ambos sistemas de trabajo, como son el alto grado de subjetividad en los croquis y las deformaciones en los calcos, problema al que ya se refiere E. Hernández-Pacheco en 1919 comparando fotos y calcos de los mismos motivos de San Román de Candamo (1919, lám. XIX). Sin olvidar la temprana llamada de atención ante los dañinos efectos del calco sobre soportes rocosos (CARTAIlHac y BReuil 1906; HeRnández-PACHeCo 1924) ${ }^{21}$.

${ }^{21}$ Sin embargo, no todos comparten este temor. Valga como ejemplo la actitud del Sr. Aznar, profesor de la Escuela de Artes e Industrias de Madrid, quien, cuando se plantea la formación de una comisión española para el estudio de Altamira, defiende el uso del calco para la reproducción de los policromos, debido a la mayor exactitud de dicho método de trabajo. Ya 


\section{LA FOTOGRAFIA}

La Fotografía, método por excelencia en la actualidad para la reproducción del Arte Rupestre, es el fruto de diversas tentativas llevadas a cabo en los campos de la Física y la Química, y aunque son varios los que se atribuyen el invento, a quien corresponde verdaderamente el mérito es a N. Niépce (1765-1833), posteriormente asociado con Daguerre. La fotografía se puede considerar inventada con toda seguridad hacia 1816 y la primera conocida data de unos diez años después (Sougez 1991).

El nuevo invento será rápidamente aplicado a la reproducción de Antigüedades. Como señala Dorell (1989), existen testimonios de mediados del siglo $x \mid x$ en Francia e Inglaterraa, como las fotografías de diversos monumentos de Egipto y Nubia del francés $M$. de Camp o el intento del Museo Baritánico de reproducir por este sistema su rica colección de tablillas cuneiformes.

Ya en 1905, MARTEl hace una importante defensa del uso de la Fotografía para los trabajos de Arte Rupestre: "Je ne m'explique vraiement pas pourquoi les chercheurs de gravures préhistoriques n'on pas fait jusqu'à présent plus fréquent appel à la photographie magnésienne, tout au moins comme adjuvant controlé. Ses opérations sont compliqués certes, mais nullement impossibles ni vaines! II suffit de s'y faire la main et d'y recourrir avec sagacité" $(1906,134)$ y $\mathrm{M}$. Boule remarca su poder por encima de los dibujos, "quels que soient leur beauté et leur mérite artistique» (1909, 390-391). En España una de las primeras referencias al respecto se debe a Góngora y Martínez en 1868 (pág. 69 de dicha obra).

De más de 400 estaciones artísticas conocidas hasta 1921 apenas llegan al centenar las que fueron fotografiadas y aún disminuye el número si se consideran exclusivamente las tomas centradas en motivos artísticos y no en el "contexto" rupestre. Ante ello cabe preguntarse si la explicación es de tipo económico o habría que pensar más bien en una mayor confianza de los investigadores en otros métodos de reproducción, fundamentalmente calco directo y dibujo a mano alzada. De cualquier manera, lo que es evidente es que el papel de la fotografía en los estudios de Arte Rupestre se va consolidando con el paso del tiempo hasta alcanzar la indiscutible hegemonía que detenta en la actualidad.

se ha visto como Cartailhac y Breuil utilizan el calco en 1902 y no sólo para la reproducción de grabados, causa, según Alcalde del Río, de que algunos motivos perdieran su pátina original. En La Valltorta no se duda, incluso, en perfilar a lápiz las figuras para su mejor identificación en los calcos. 
Lamentablemente, la información con que se cuenta para el análisis de las primeras fotografías de Arte Rupestre en España es escasa y fragmentaria, todavía más pobre que en el caso de Croquis y Calcos. Por otra parte, no debe olvidarse que se están viviendo los momentos de gestión y primeros ensayos del nuevo invento, lo que queda patente en la calidad final de buena parte de los trabajos realizados.

\subsection{Fotografía en blanco y negro}

La más temprana mención al respecto parece ser el intento del año 1880 en Altamira: se sabe que con esa fecha J. Vilanova se dirige al Ministerio de Fomento con el fin de conseguir los aparatos necesarios para obtener diversas fotografías en el interior de la caverna, sin que exista unanimidad de opiniones sobre el resultado final. Así, en un artículo de El Cántaro con fecha de 1 de enero de 1881, firmado con las iniciales B. $T$., se dice que las fotografías no llegaron a obtenerse, idea que mantiene Aujoulat (1987) y a la que se oponen otros investigadores, como Madariaga y Sanemetrerio (1976), y más recientemente Sougez (1991).

Por tanto, habrá que esperar unos años, concretamente hasta 1902 , para que se realicen con seguridad fotografías en Altamira, en este caso gracias a la cámara de E. Cartailhac. Efectivamente, el prehistoriador francés obtiene numerosas tomas, tanto de la caverna como de diferentes motivos de la misma, parte de las cuales ilustran la Monografía de 1906. Como se explica en el libro, estas fotografías se concebian como un instrumento de control y de información complementaria de los calcos y dibujos realizados. También de muy principios de este siglo o finales del pasado se conservan algunas fotografías de petroglifos del Noroeste (fig. 10).

Sin embargo, la mayor parte del material fotográfico conservado se fecha entre 1910-15, período de gran actividad, y corresponde fundamentalmente a J. Cabré. Las más antiguas producciones de Cabré evidencian la estrecha relación del prehistoriador con su tierra, Teruel: Calapatá (¿1905-8?), Peñalba (1909-10), yacimientos de Albarracín (1909-10), para luego ir extendiendo su actividad por toda la Península, de Cogul a las Batuecas y de Eira d'os Mouros a numerosas estaciones gaditanas. Conjuntos Paleolíticos como San Román de Candamo, levantinos como Els Secans, esquemáticos e incluso grabados de difícil atribución cronológica, como los de Soria, son recogidos por el objetivo de la cámara de Cabré.

Entre los trabajos de $\mathrm{H}$. Obermaier merece especial mención el realizado en La Pasiega (Santander), que sirve para ilustrar la monografía 


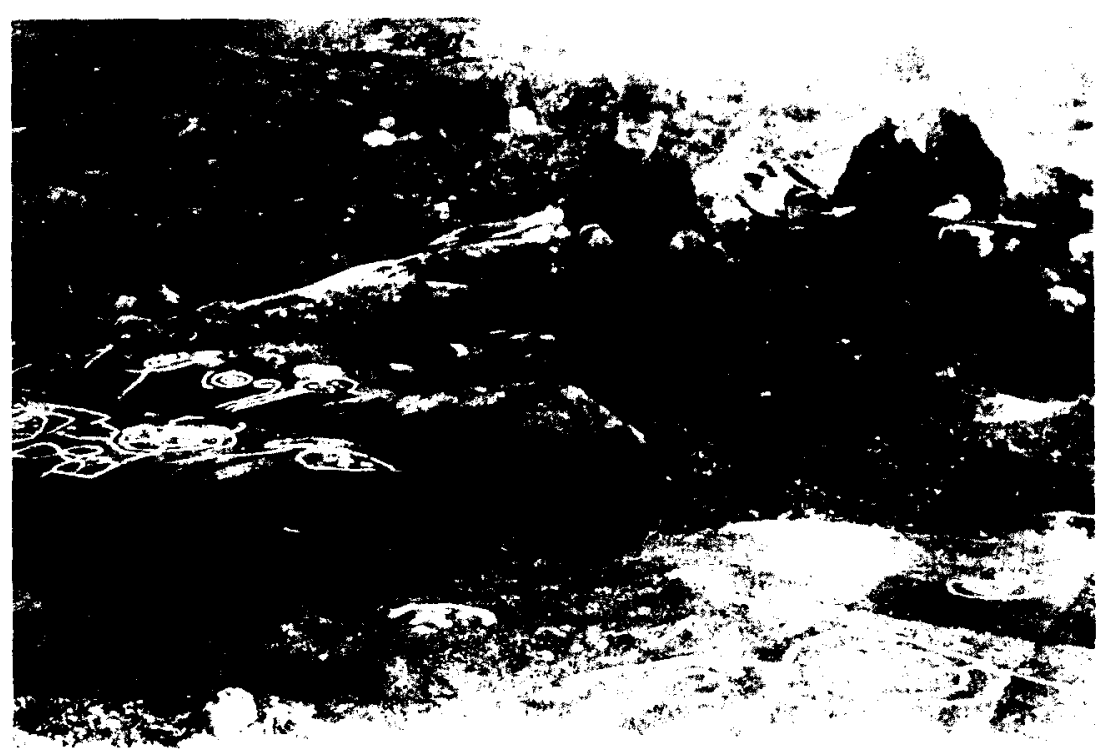

Fig. 10. Outeiro da Mina, segun fotografia de la Sociedad Arqueológica de Pontevedra (Martinez Murgía, 1901-5; t. I; lam. IV).

aparecida en 1913, tercer volumen del Corpus del Príncipe de Mónaco dedicado a España. Tampoco hay que olvidar la labor de los HernándezPacheco, padre e hijo, especialmente este último, pues como ayudante técnico de la Comisión de Investigaciones Paleontológicas y Prehistóricas, se encarga de estos menesteres en numerosas campañas, como la de Penches (Burgos) de 1916, o la de las Cuevas de la Araña (Valencia) algunos años después.

Sin embargo, no está demasiado clara la aportación de $H$. Breuil a este campo y más bien parece que el prehistoriador francés se reserva las labores de dibujo y calcado, dejando en manos de colaboradores las reproducciones fotográficas, lo que acrecienta el interés de varias instantáneas obtenidas por el propio Abate (Atapuerca, El Silo, Vélez Blanco) y que se conservan en el Museo de Ciencias, bien es cierto que con una calidad bastante discutible. Pertenecen a las primeras compañas de $\mathrm{H}$. Breuil en España, cuando contaba con la colaboración técnica del joven Cabré.

A la labor de los propios investigadores se suma la de toda una serie de fotógrafos que realizan ocasionalmente trabajos en España, como M. C. Lasalle, quien viene a nuestro país por encargo del Príncipe de Mónaco, para colaborar con $\mathrm{H}$. Breuil en la reproducción de las cuevas del norte. 
Lasalle permanece en la zona Cantábrica por espacio de unos 15 días durante el mes de abril de 1909 y realiza fotos en Santián, Clotilde, Venta la Perra, Aguas de Novales, Altamira, Castillo, La Loja, Pindal, Covalanas, Pendo, Haza, etc. A este fotógrafo se deben la mayoría de las planchas que ilustran la monografía de Les Cavernes de la Région Cantabrique, publicada en $1911^{22}$. Otras fotografías de esta misma obra llevan la firma de M. Bourée, Ayuda de Campo del Príncipe Alberto, y son obtenidas en el curso de una corta visita durante el verano de 1909.

En general, las estaciones artísticas más fotografiadas son Paleolíticas y, más en concreto del norte: Altamira, El Castillo, La Pasiega a las que se añade la cueva malagueña de La Pileta. Por el contrario, sitios tan importantes como Gogul sólo cuentan con algunas reproducciones del paisaje que rodea al abrigo.

Lo normal, dado el corto período de tiempo considerado, es que no se lleve a cabo más que una campaña de reproducción en cada estación; sin embargo, existen excepciones, como Altamira, Las Batuecas o la Valltorta. Los bellos abrigos del barranco castellonense son fotografiados por las diversas comisiones e investigadores que estudian el conjunto desde que se reciben las primeras noticias de su existencia a fines del invierno de 1917: C.I.P.P. (H. Obermaier); Institud d'Estudis Catalans; R.A.H. (L. Arco), R.S.E.H.N.; Barón de Alcahalí y J. Cabré.

\subsection{Fotografía en color}

El intento de reproducir los colores en la superficie sensible de la placa va unido a los comienzos de la Fotografía y, aunque hay experiencias anteriores, habrá que esperar a 1869, con C. Cros y L. Ducos du Hauron y su solución de la tricromia o selección de los tres colores primarios, que está en la base de todos los métodos de la Fotografía en Color. Con posterioridad se irán sucediendo otros sistemas, hasta que en los años cuarenta se produzca la irrupción masiva del color (Sougez 1991).

Sin embargo, hasta 1921 el recurso a placas policromas para la reproducción de motivos rupestres es escaso y puntual, si bien ya desde principios de siglo su uso era defendido por diversos investigadores (Boulé 1909).

22 Entre los trabajos de Lasalle destaca el de Font-de-Gaume (Perigord), con Capitán, Breuil y Peyrony, publicado en 1910 . 


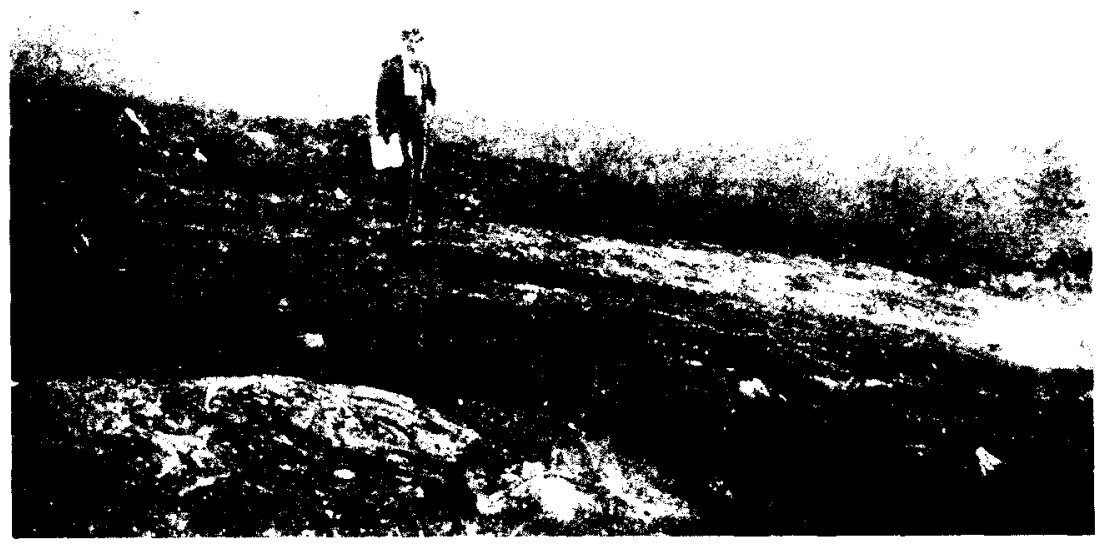

Fig. 11. El dibujante E. Campo junto a un petroglifo (Garcia Alen y Peña Santos, 1981).

Existen referencias de trabajos en color efectuados por $\mathrm{J}$. Cabré entre los años 1911-14 en Peña Escrita, Albarracín, Cueva de los Letreros o las Batuecas ${ }^{23}$, Cogul y en Cantos de la Visera y Cueva del Mediodía, sin que ninguna fuera publicada, seguramente, como tantas otras veces, por motivos económicos.

\subsection{Análisis de la producción fotográfica}

De igual manera que en Croquis y Calcos, también en las fotografías se tiende a la elección de figuras aisladas o pequeños conjuntos.

No es frecuente que aparezcan escalas, salvo que se considere como tal el recurso a colocar personas junto a los motivos artísticos, papel que desempeñaría el dibujante $E$. Campo Sobrino en una vista del conjunto de Outeiro do Lombo da Costa (Pontevedra), obtenida a principios de siglo (Fig. 11), mientras que en la cueva santanderina de Covalanas se

${ }^{23}$ En este caso y en el anterior se duda entre J. Cabré y $\mathrm{H}$. Breuil a la hora de establecer la autoría. 

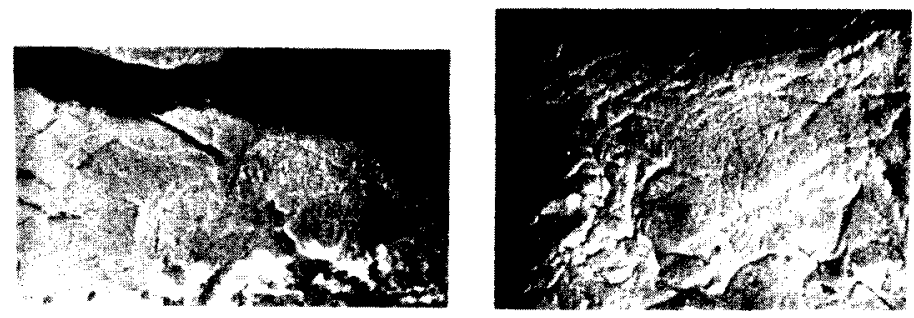

Fig. 12. El Buxu: fotos y croquis de lectura de la CIPP (Catálogo Exposición, 1921, lam. XIII).

opta por colocar una cerilla al lado de una de las pinturas (ALCALDE, BREUIL y Sierra 1911, foto 32).

Es muy corriente el croquis de lectura, que a menudo se hace imprescindible para leer correctamente los paneles decorados (Fig. 12). Se trata de un calco o dibujo que se colora junto o sobre la fotografía, no siendo extraño que incorpore datos relativos al estado de conservación, medidas, etc. de los motivos rupestres. Los croquis de lectura para la producción fotográfica de la C.I.P.P. son obra del dibujante Fco. Benítez Mellado.

En general, la calidad del material fotográfico no es demasiado elevada y resulta frecuente que las figuras se corten, que el encuadre no sea correcto o que existan problemas de iluminación. Es por ello que el retocado, práctica unánimemente rechazada en nuestros días, es relativamente frecuente e incluso indispensable. Lamentablemente, el hecho de trabajar fundamentalmente con material publicado no permite aventurar demasiados juicios de valor. De ahí el interés de la colección de fotografías del Museo de Ciencias de Madrid que permite sacar a la luz aspectos que se pierden en el momento de la publicación, como los retoques de que eran objeto ciertas fotografías con el fin de disimular fallos, a veces con un espíritu muy artístico, como el que lleva a J. Cabré a añadir nubes 
en unas vistas de Cogul (Lérida) y de la Fuente del Cabrerizo (Teruel), como remedio al excesivo ennegrecimiento del cielo.

\subsection{Técnicas y aparatos}

Apenas existe información sobre aparatos o técnicas, aunque es claro que, a lo largo de todo el período, las máquinas fotográficas se van perfeccionando y disminuyendo de tamaño, con lo que se hacen más cómodas y manejables. También avanza la óptica, con nuevos modelos de objetivos y obturadores y la reducción del tiempo de exposición permite prescindir más fácilmente del trípode.

No es extraño el recurso a diversos procedimientos que facilitan la reproducción de los motivos en la placa sensible, desde humedecer la roca, en el caso de pintura, a marcar los surcos con tiza o carbón cuando de grabado se trata (Vide Fig. 10). Esta última solución, empleada por Cabré y González del Río al fotografiar los petroglifos de Punta Herminia y el Polvorín (Coruña), es norma en los trabajos con este tipo de testimonios grabados a juzgar por numerosas fotos de la Sociedad Arqueológica de Pontevedra (Outeiro da Mina, Outeiro do Lombo da Costa, etc.).

Cuando los grabados se localizan en el interior de cuevas, la C.I.P.P. recomienda el uso de lámparas potentes sin reflector, que iluminan lateralmente, con exposición larga y diafragma de poca abertura, sistema seguido en el Buxu (Asturias), según relata Hernández-Pacheco en 1959. Se rechaza así el fogonazo de magnesio, más rápido, pero con el problema del humo que impide trabajar en las horas siguientes. A pesar de estas limitaciones, J. Cabré recurre al magnesio en San Román. En Bicorp (Valencia), Fco. Hernández-Pacheco se servirá de exposiciones variables, de medio a dos segundos, con poca abertura de diafragma, siendo el principal problema el escaso contraste con el fondo rocoso.

Uno de los trabajos que mejor se conoce, desde el punto de vista de la metodología utilizada, es el del espeleólogo $\mathrm{M}$. Martel, realizado en Altamira durante una corta visita el 24 de abril de 1905 en compañía de Alcalde del Río y que será presentado en el / Congrés Préhistorique celebrado en Périgeux en ese mismo año. Para dicha ocasión, Martel combina dos angulares diferentes: un gran angular Jumelle Universal Bellienni, para las distancias casi nulas, y otro normal. Los cambios de altitud del techo le impiden usar trípode, por lo que tiene que colocar la cámara entre las piedras y verificar el campo del visor «a ojo».

En ocasiones no se duda en recurrir a la ayuda de elementos "externos", como el espejo con el que se enfrentan Lasalle a varias vistas del 
techo de Altamira o Alcalde y Mengaud a un difícil bisonte de Hornos de la Peña, si bien estos últimos, poco satisfechos con el resultado final, renuncian a publicarlo.

De cualquier manera, es claro que en estos momentos todavía resultaba difícil la obtención de buenas fotografías como ponen de relieve las numerosas alusiones al respecto, que hablan de deformaciones, dificultades para trabajar en el interior de cavidades $y$, muy especialmente, de problemas de iluminación.

\section{LOS MOLDES}

Este rápido recorrido por los principales sistemas de Reproducción de Arte Rupestre utilizados en España hasta 1921, no puede dejar de mencionar otro método de trabajo, de uso muy puntual y, por tanto, poco significativo en estas tempranas fechas, pero que posteriormente adquirirá una mayor importancia. Nos estamos refiriendo a los moldes.

\section{III.1. Molde indirecto}

La primera referencia parece ser el bisonte de Altamira que el hijo del Conde de Moriana modela en cera durante una visita a la caverna en el año de 1880 , según relata $A$. de los Ríos y Ríos en El Eco de la Montaña del 14 de noviembre de 1880. Lamentablemente, nada se sabe del destino posterior de este curioso experimento en el que se trata incluso de reproducir el colorido original, para conseguir un mayor realismo.

\section{III.2 Molde directo}

Ya en la Exposición Universal de París de 1900 se expone un molde directo de un bóvido de La Mouthe, realizado por E. Rivière con arcilla y yeso. Sin embargo, la primera mención para España no parece ser anterior a 1923, año en que F. Font, escultor del Laboratorio del Servicio de Investigaciones del Institut d'Estudis Catalans, realiza un molde directo del friso de Cogul (Lérida), incluido en la "Sección Monumental» de la Exposición Internacional de Barcelona de 1929, junto a otro molde de Peñatu (Asturias), del que nada se sabe sobre autor y fecha de realización ${ }^{24}$

${ }_{24}$ Se puede ver la fotografía del molde de Peñatú en el Catálogo publicado por Boch Gimpera con motivo de la Exposición. 
A pesar de las escasas referencias conservadas, la técnica de molde no parece desconocida en España, pues, según reseña del Conde de Cedillo en el Boletín de la Sociedad Española de Excursiones de 1931, los grabados prehistóricos descubiertos por el Padre Tuñón hacia 1922 entre la villa de Santa María de Nieva y el pueblo de Ochando (Segovia) son reproducidos en escayola y enviados al Conde de la Vega del Sella.

\section{N. CONCLUSIONES}

Vario son los aspectos que se pueden concluir sobre la metodología de trabajo utilizada por los pioneros del Arte Rupestre en España hasta el año 1921:

1. Se sirven de los limitados medios técnicos de la época para lograr un progresivo perfeccionamiento en la lectura y registro de los datos. Dibujo a Mano Alzada, Calco Directo y Fotografía van a ser los sistemas mayoritariamente utilizados, a los que se unen otros más minoritarios, como el Molde, constatándose ya esa dualidad entre sistemas directos e indirectos que, con los avances y perfeccionamientos lógicos de la técnica, han llegado hasta nuestros dias

2. Los primeros trabajos de reproducción de Arte Rupestre se rigen por criterios eminentemente estéticos y la determinación de la imagen primera sobre el análisis tecnológico del trazo o el establecimiento de relaciones entre la obra y su soporte (AujOULAT 1987), lo que se explica porque la reproducción se entiende más como prueba o testimonio de la existencia de los conjuntos rupestres que como método de análisis en si mismo.

3. Etapa de grandes individualidades, cuyo trabajo se caracteriza por una gran libertad metodológica. A destacar los nombres de Alcalde del Río, Fco. Benítez Mellado, H. Breuil, E. Campo y J. Cabré, con una labor en muchos casos no superada en la actualidad, tanto desde el punto de vista cualitativo como cuantitativo.

4. La destrucción progresiva, natural y antrópica, de cuanto se entiende por Arte Rupestre, nos priva de la integridad de estos testimonios, hasta el punto de que, en no pocas ocasiones, la documentación gráfica generada en los primeros estudios sigue siendo la fuente principal para valorar el contenido artístico de numerosos lugares desaparecidos, mutilados e incluso, aunque parezca extraño, marginados o no investigados con más intensidad que la de los comienzos de esta parcela de la Prehistoria.

5. Sin embargo, el escaso interés, tanto de los propios autores como de la investigación posterior, explica la pobre información con la que se cuenta. Desinterés que ha permitido la pérdida de buena parte de la do- 
cumentación original o el olvido de la misma entre los fondos de diversas instituciones.

\section{BIBLIOGRAFIA}

AlCALDE DEL Río, H. (1906): “Las pinturas y grabados de las cuevas prehistóricas de Santander (Altamira, Covalanas, Hornos de la Peña, Castillo)»; Portugalia, ll. Oporto.

ARANZADI, T.; BaAANDIARAN, J.M. y Euguren, E. (1925): Exploraciones en la caverna de Santimamiñe (Basondo, Cotézubi). Memoria l: Figuras Rupestres.

Aujoulat, N. (1987): Le relevé des oeuvres pariétales paléolithiques. Enregistrement et traitement des données; D.A.F., n. ${ }^{\circ}$. París.

Beltrán, A. (1981): "Metodología del trabajo sobre el terreno"; Caesaraugusta, 53-54. Zaragoza, págs. 133-137.

Benitez Mellado, Fco. (1959): «Pinturas Rupestres Españolas», Cuadernos de la Biblioteca Municipal de Bujalance, $n{ }^{\circ}$ 3. Córdoba. Cataloguillos de Exposiciones (1940): $2 d a$. Exposición: Enrique Campo (1890-90) y sus precendentes. Museo de Pontevedra.

Bosch GIMPERA, P. Y Colominas, J.M. (1921-26): "Pintures i gravats rupestres", A.I.E.C., VII. Barcelona, págs. 3-27.

B.T. (1881): “Operibus credite et non verbis”, El Cántabro, 19. Torrelaguna; págs. 1-2.

CABRÉ, J. y G. DEL Rio, J. (1915): “Los grabados rupestres de la Torre de Hércules (La Coruña)», Rev. de Archivos, Bibliotecas y Museos. Madrid, 19 págs.

Clottes, J. (1989): "Recherche et conservation: problémes de déontologie" L'art Pariétal Paléolithique, Colloque Int. de Perigueux le Llotht, 1984. París, págs. 219-222.

ChABREDIER, I. (1966): “Etude méthodologique des relevés d'art parietal préhistorique», B.S.P.F.,63. Paris, págs. 501-512

DELLUC, B. y G. (1984): “Lécture analythique des supports rocheux gravés et relevé synthétique», L'Anthropologie, 88,4, págs. 519-529.

Dorell, P. (1989): Photography in Archaeology and Conservation. Cambridge Manuals in Archaeology.

Garcia Alen, y Peña Santos, A. (1980): Grabados rupestres de la provincia de Pontevedra. Pontevedra.

Góngora y Martínez, M. (1868): Antigüedades Prehistóricas de Andalucía. Madrid.

HERNÁNDEZ-PACHECO, E. (1924): Las pinturas prehistóricas de las Cuevas de la Araña (Valencia). Evolución del Arte Rupestre en España, CIPP, 34.

- (1959): Prehistoria del Solar Hispano. Orígenes del Arte Rupestre. Madrid, Real Academia de Ciencias Exactas, Físicas y Naturales.

LeRoI-GouRham, A. (1950): Les fouilles préhistoriques (technique et méthodes). Paris.

Madafiaga, B. (1972): Hermilio Alcalde del Rio. Una escuela de Prehistoria en Santander. Santander.

Madariaga, B. y Sanemeterio, M. (1976): Marcelino Sanz de Sautuola. Escritos y Documentos. Santander.

MARTEL, M. (1906): “Réflexions sur Altamira: l'âge des gravures et des peintures des cavernes", I Congrés Préhistorique de France, Périgueaux, 1905. París, págs. 112-136.

Martínez Murgia, M. (1901-5): Historia de Galicia. La Coruña; II vols. Memorias de la Junta Superior para la Ampliación de Estudios. 1907-1921. Madrid.

Moneva Montero, M. ${ }^{a}$ D. (1992): Inicios Historiográficos del Arte Rupestre en España. De Altamira a la Exposición de 1921. Memoria de Licenciatura. U.A.M. Inédita.

Ripoll Perelló, E., (1964): "Vida y obra del Abate Henri Breuil, Padre de la Prehistoria", Miscelanea al Abate Henri Breuil, T. I; págs. 1-71.

SANZ DE SAUtuOla, M. (1880): Breves apuntes sobre algunos objetos prehistóricos de la provincia de Santander. Santander.

ServelLe, C. (1990): "Les relevés d'art mobilier lithique"; Colloque int. L'art des Objets au Paléolithique. Foix-Le Mas-d'Azil. 1987. Clemency 1990; T. II; 245-251 
SOCIEDAD ESPAÑOLA DE AMIGOS DEL ARTE (1921): Exposición de Arte Prehistórico Español. Catálogo-guia. Madrid.

Sougez, M. ${ }^{2}$ L. (1991): "Historia de la Fotografia", Cuadernos de Arte Cátedra. Madrid.

\section{COLECCIONES}

* Memorias C.I.P.P. Serie Prehistórica.

* Les Peintures et Gravures Murales des Cavernes Paléolithiques. 